\title{
The value of the hedgehog signal in osteoblasts in fluoride-induced bone-tissue injury
}

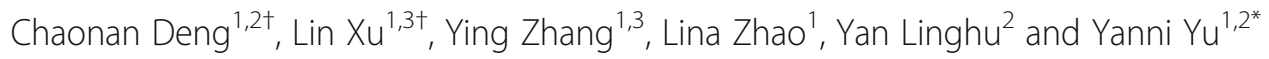

\begin{abstract}
Objective: This study was designed to observe the expression of important hedgehog $(\mathrm{Hh})$ signal factors in the bone tissue of rats with chronic fluorosis and cultured osteoblasts in order to investigate the role and significance of the Hh signal in fluoride-induced bone injury.

Methods: Healthy Sprague-Dawley (SD) rats were randomly divided into four groups: the control group, the fluorosis group ( $F$ Group), the fluoride + blocker group ( $F+C y c l$ group: rats were treated with fluoride + cyclopamine), and the fluoride + blocker control group ( $F+D M S O$ group). After 6 months of intervention, the urinary fluoride content of rats in each group was detected. The primary osteoblasts of rats were selected for cell experiment, and the experiment was carried out after the cells were passaged from the second to the fourth generation.

(Continued on next page)
\end{abstract}

\footnotetext{
*Correspondence: yuyanni_87459@163.com

${ }^{\dagger}$ Chaonan Deng and Lin Xu contributed equally to this work.

'Department of Pathology, Affiliated Hospital of GuiZhou Medical University,

No. 28 of Guiyi Street, Guiyang 550004, China

${ }^{2}$ Department of Pathology, GuiZhou Medical University, Guiyang 550004,

China

Full list of author information is available at the end of the article
}

(C) The Author(s). 2021 Open Access This article is licensed under a Creative Commons Attribution 4.0 International License, which permits use, sharing, adaptation, distribution and reproduction in any medium or format, as long as you give appropriate credit to the original author(s) and the source, provide a link to the Creative Commons licence, and indicate if changes were made. The images or other third party material in this article are included in the article's Creative Commons licence, unless indicated otherwise in a credit line to the material. If material is not included in the article's Creative Commons licence and your intended use is not permitted by statutory regulation or exceeds the permitted use, you will need to obtain permission directly from the copyright holder. To view a copy of this licence, visit http://creativecommons.org/licenses/by/4.0/. The Creative Commons Public Domain Dedication waiver (http://creativecommons.org/publicdomain/zero/1.0/) applies to the data made available in this article, unless otherwise stated in a credit line to the data. 
(Continued from previous page)

Results: The proliferation rate of primary rat osteoblasts presented time-affected and dose-affected relationships in a short time under treatment with a low dose of sodium fluoride (NaF), but the proliferation of osteoblasts was inhibited by long-term and high-dose NaF exposure. In the F group, the alkaline phosphatase (ALP) activity of osteoblasts increased gradually. The ALP activity was lower in the F + Cycl group than in the F group, and there was no significant difference between the F + DMSO group and F group. With the increase in fluoride exposure, the expression of Hh signal factors and osteogenic-related factor proteins increased gradually. The expressions of Indian hedgehog (Ihh), smoothened (Smo), Glioma-associated oncogene homolog (Gli) 2, and Runt-related transcription factor 2 (Runx2)in the F + Cycl group increased with the dose of fluoride but they were significantly inhibited compared with the F group. Compared with the control group, the content of urinary fluoride in the $F$ group was significantly higher $(P<0.05)$, but there was no significant change in urinary fluoride content in the $F+$ Cycl group and the F + DMSO group. Compared with the control group, the serum bone alkaline phosphatase (BALP) contents of rats in the other groups increased after 6 months' intake of fluoride water $(P<0.05)$. After drug blocking, the serum BALP content in the F + Cycl group was lower than that in the $F+$ DMSO group $(P<0.05)$. The BALP content in the F + DMSO group was similar to that in the F group: it did not decrease. The mRNA expressions of Ihh, Smo, Gli2, and Runx2 in bone tissue of the F group were significantly higher than those in the control group $(P<0.05)$. After cyclopamine blocking, the expressions decreased $(P<0.05)$, but the differences between the $F+$ DMSO group and $F$ group were not statistically significant.

Conclusion: Hh signal plays an important role in fluoride-induced bone injury. The effective inhibition of cyclopamine is expected to be a new target for the treatment of skeletal damage caused by fluorosis.

Keywords: Osteoblasts, Hh signal, Fluorosis, Bone-tissue injury, Skeletal fluorosis

\section{Introduction}

Endemic fluorosis is a systemic, chronic, toxic disease characterized by skeletal fluorosis and dental fluorosis, which is caused by the long-term intake of fluorine by residents through drinking water, food, air, and other means that exceeds normal physiological needs. It is one of the most widespread and serious endemic diseases in China [1]. After the implementation of prevention and control measures, such as improvements to the water supply and to stoves, the prevalence of endemic fluorosis has been partially controlled. However, due to the complexity of the natural or ecological environment, the pathogenesis of endemic fluorosis is not very clear [2, 3]. Mak et al. found that selective upregulation of the Hh signal in mature osteoblasts could lead to significant increases in osteogenesis and bone resorption [4]; this is very similar to the pathology of skeletal fluorosis observed in many previous studies. Therefore, we speculate that the hedgehog $(\mathrm{Hh})$ signal may affect the balance of bone remodeling by participating in the differentiation, proliferation, and apoptosis of osteoblasts and accordingly play an important role in the occurrence and development of skeletal fluorosis.

This study was designed to observe the expression of important $\mathrm{Hh}$ signal factors in the bone tissue of rats with chronic fluorosis and cultured osteoblasts in order to investigate the role and significance of the $\mathrm{Hh}$ signal in fluoride-induced bone injury.

\section{Materials and methods \\ Cell culture}

The primary osteoblasts of rats were taken from the skulls of specific pathogen-free (SPF) Sprague-Dawley (SD) rats (provided by the Animal Experimental Center of Guizhou Medical University) aged 24-48 h. These were used for cell experiments after being passaged from the second to the fourth generation.

\section{The experimental group}

The present study meets the requirements of the Declaration of Helsinki of the World Medical Association and has been approved by the Ethics Committee of our hospital. In this study, 48 healthy SD rats (100-120 g) (Medical Laboratory Animal Center, Daping Hospital, the Third Military Medical University, Certificate No. SCXK [Yu] 2007-0005) were used. These rats were randomly divided into four groups: the control group, the fluorosis group (F Group), the fluoride + blocker group $(\mathrm{F}+\mathrm{Cycl}$ group: rats were treated with fluoride + cyclopamine), and the fluoride + blocker control group $(\mathrm{F}+$ dimethyl sulfoxide [DMSO] group). There were 12 rats in each group; half were males and the half were females in each group. All groups of rats were fed with standard solid feed (fluorine content less than $1 \mathrm{mg} / \mathrm{kg}$ ) prepared by the Animal Center of Guizhou Medical University. The rats in the control group were given tap water (fluorine content $<1 \mathrm{ppm}$ ). In the F group, the tap water had $50 \mathrm{ppm}$ of sodium fluoride $(\mathrm{NaF})$ added. In the $\mathrm{F}+$ Cycl group, after 6 months of feeding with tap water 
containing $50 \mathrm{ppm}$ of $\mathrm{NaF}$, the rats were injected intraperitoneally with $10 \mathrm{mg} / \mathrm{kg}$ of cyclopamine while continuing the fluoride intake, q.o.d., three times in total. In the F + DMSO group, after 6 months of feeding with tap water containing $50 \mathrm{ppm}$ of $\mathrm{NaF}$, the rats were injected intraperitoneally with $10 \mathrm{mg} / \mathrm{kg}$ of DMSO while continuing the fluoride intake, q.o.d., three times in total. The urinary fluoride content of the rats in each group was detected. Some epiphyseal tissues from the femoral shaft were fixed with neutral formalin and decalcified with ethylenediaminetetraacetic acid (EDTA). The rest of the bone tissues were preserved at $-80{ }^{\circ} \mathrm{C}$.

\section{Main reagents and instruments}

Cyclopamine (Selleck, USA); rat serum ELISA Kit (bone alkaline phosphatase [BALP], R\&D, USA); rabbit antimouse polyclonal antibodies Ihh, Smo, Gli2, and Runx2 (Santa Cruz, USA); diaminobiphenyl amine (DAB, Guangzhou Ascend Biotechnology Co., Ltd., China); enzyme micro-plate reader (Bio-Rad, USA); real-time polymerase chain reaction (PCR) machine (Applied Biosystems, USA).

\section{Experimental methods}

\section{Culture and identification of rat primary osteoblasts}

Osteoblasts from the calvaria of the newborn rats were isolated by secondary enzyme digestion and cultured, and the purity of the osteoblasts was determined by alkaline phosphatase staining.

Determining the use concentration of NaF and cyclopamine After $72 \mathrm{~h}$ of cell subculture, different amounts of $\mathrm{NaF}$ solution were added into the cell culture medium to make final concentrations of $\mathrm{NaF}$ solution of $0 \mathrm{mg} / \mathrm{L}, 2.5$ $\mathrm{mg} / \mathrm{L}, 5 \mathrm{mg} / \mathrm{L}, 10 \mathrm{mg} / \mathrm{L}$, and $20 \mathrm{mg} / \mathrm{L}$, respectively. Then the cells were cultured at different concentrations for 24 $\mathrm{h}, 48 \mathrm{~h}$, and $72 \mathrm{~h}$. The CCK 8 method was used to detect the cell proliferation rate to determine the suitable concentration of fluoride.

The proliferation rate of the cultured cells was measured after $24 \mathrm{~h}, 48 \mathrm{~h}$, and $72 \mathrm{~h}$ of treatment with cyclopamine (the final concentration was $0 \mu \mathrm{mol} / \mathrm{L}, 5 \mu \mathrm{mol} /$ $\mathrm{L}, 10 \mu \mathrm{mol} / \mathrm{L}$, and $20 \mu \mathrm{mol} / \mathrm{L})$ to determine the best dosage.

\section{Detection of the urine's fluorine content}

The $24 \mathrm{~h}$ urine of all rats was collected and the fluoride content in the urine was detected by the fluoride ion selective electrode method.

\section{Determination of the serum bone alkaline phosphatase}

Blood was sampled from the femoral arteries of the rats, centrifuged, and the upper serum was used to determine the BALP level, following the steps in the instructions of the kit.

\section{Bone histopathology}

The epiphysis of the femoral shaft of the rats was obtained, fixed with $4 \%$ neutral formaldehyde, decalcified with EDTA, embedded with paraffin, and then underwent hematoxylin and eosin (H\&E) staining. The trabecular width, trabecular density, and cortical thickness were measured at $1 \mathrm{~mm}$ below the epiphyseal line of the femoral metaphysis.

\section{Detection of the mRNA of the Hh pathway and osteogenic- related factors}

The total RNA of the rat bone tissue and the cultured osteoblasts was extracted and reversely transcribed into cDNA using random primers. A real-time PCR of the gene to be tested was carried out. The primers were designed and synthesized by Shanghai GeneCore Bioengineering Co., Ltd. Reaction conditions: pre-denaturation at $95{ }^{\circ} \mathrm{C}$ for $10 \mathrm{~min}$, with the reaction terminated after 40 cycles at $95{ }^{\circ} \mathrm{C}$ for $15 \mathrm{~s}$ and at $60{ }^{\circ} \mathrm{C}$ for $30 \mathrm{~s}$. At the end of the reaction, the software automatically generated the $\mathrm{Ct}$ value, and $2^{-\triangle \mathrm{Ct}}$ was calculated for comparison. The primer sequences were as follows: Runx2: forward primer 5-ACAGCACCTTCAGCACTCT-3, reverse primer 5-AAGTTCTTGGCTATTACGACA-3.

\section{Detection of the protein of the Hh pathway and osteogenic- related factors}

Immunohistochemistry (IHC) and western blot were used to observe the location and expression of the $\mathrm{Hh}$ pathway and osteogenic-related factors.

IHC The sections were dewaxed, incubated with $3 \%$ $\mathrm{H}_{2} \mathrm{O}_{2}$ for 20 min, repaired with high pressure for 2.5 min, naturally cooled down to room temperature, and incubated with blocking buffer for $25 \mathrm{~min}$. Then, the blocking buffer was discarded without washing, and the sections were dropped with diluted primary antibody and left standing at $4{ }^{\circ} \mathrm{C}$ overnight. The next day, the sections were taken out and rewarmed for $5 \mathrm{~min}$, a second antibody was added for $25 \mathrm{~min}$ then horseradish peroxidase was added for $25 \mathrm{~min}$. The sections were colored with $\mathrm{DAB}$, then the reaction was terminated with flow water and the sections were counterstained with hematoxylin, dehydrated, treated with xylene until they became transparent, and sealed.

Western blot The total RNA of the rat bone tissue and cultured osteoblasts was extracted, lysated on ice with a radio-immunoprecipitation assay (RIPA) lysis buffer, and phenylmethylsulfonyl fluoride (PMSF) for $1 \mathrm{~h}$, and centrifuged at $2500 \mathrm{rpm}$ and $4{ }^{\circ} \mathrm{C}$ for $30 \mathrm{~min}$. Then the 
protein concentration was determined by the $\mathrm{BCA}$ method. Equal amounts of total protein $(40 \mu \mathrm{g})$ of protein were taken to undergo polyacrylamide gel electrophoresis (PAGE), electro-transferred to a polyvinylidene fluoride (PVDF) membrane, and blocked with $1 \times$ Tris buffered saline/Tween (TBS-T) solution containing 5\% bovine serum albumin (BSA) for $1 \mathrm{~h}$. Then, the first antibodies, Ihh (1:200), Smo (1:200), Gli2 (1:500), and Runx2 (1:500) were added, and the samples were incubated at $4{ }^{\circ} \mathrm{C}$ overnight. The second antibody (1:3000) was then added and the samples were incubated at room temperature for $1 \mathrm{~h}$ the next day, exposed and developed, and Image J gray analysis software was used for quantitative analysis.

\section{Statistical analysis}

Data were analyzed using the statistical software SPSS 20.0. Measurement data were expressed as the mean \pm standard deviation $(-x \pm S D)$, and count data were expressed as percentages (\%). Comparisons between multiple groups were conducted using univariate analysis of variance, and a post hoc test was conducted using the least significant difference (LSD). Abnormally distributed measurement data were compared among groups using a nonparametric test. Count data were evaluated using the chi-square test. $P<0.05$ was considered statistically significant.

\section{Results}

\section{Culture and identification of rat primary osteoblasts}

The primary rat osteoblasts were obtained by secondary enzyme digestion and passaged to the second generation. Osteoblasts were spindle-shaped, fusiform or triangular, with protuberance. The nuclei were elliptic. The cells were adherent to the wall, and the refraction was good. Alkaline phosphatase staining showed that there were gray-black and gray-brown deep-staining particles in the cytoplasm (Fig. 1).
Time- and dose-effect relationships between the osteoblast proliferation rate and $\mathrm{NaF}$ treatment and the screening of cyclopamine concentration

As shown by Fig. 2a, osteoblasts were treated with different concentrations of $\mathrm{NaF}$ for $24 \mathrm{~h}, 48 \mathrm{~h}$, and $72 \mathrm{~h}$. The result revealed that with the increase of fluoride dose and time, the effects of fluoride on osteoblast proliferation were different. At $24 \mathrm{~h}$ of treatment, the proliferation rate of osteoblasts was gradually increased; at $48 \mathrm{~h}$ of treatment, the proliferation rate of cells treated with $2.5 \mathrm{mg} / \mathrm{L}$ and $5 \mathrm{mg} / \mathrm{L} \mathrm{NaF}$ was increased, but the proliferation rate of cells treated with $10 \mathrm{mg} / \mathrm{L}$ and $20 \mathrm{mg} / \mathrm{L}$ $\mathrm{NaF}$ was rapidly decreased; at $72 \mathrm{~h}$ of treatment, the proliferation rate of cells treated with various concentrations of $\mathrm{NaF}$ was decreased.

As shown by Fig. $2 \mathrm{~b}$, osteoblasts were treated with different concentrations of cyclopamine for $24 \mathrm{~h}, 48 \mathrm{~h}$, and $72 \mathrm{~h}$ to select the appropriate treatment concentration of cyclopamine. The results revealed that with an increase in cyclopamine concentration $(2.5 \mu \mathrm{mol} / \mathrm{L}, 5$ $\mu \mathrm{mol} / \mathrm{L})$, the cell proliferation rate was decreased gradually. When cyclopamine concentration was $>10 \mu \mathrm{mol} /$ $\mathrm{L}$, the cell viability was significantly affected at the three time points.

The purpose of this study was to investigate the mechanism of osteoblast proliferation induced by fluoride. Therefore, in the subsequent experiment, the cells were treated with $2.5 \mathrm{mg} / \mathrm{L}$ and $5 \mathrm{mg} / \mathrm{L} \mathrm{NaF}$ for $48 \mathrm{~h}$ and then treated with $5 \mu \mathrm{mol} / \mathrm{L}$ cyclopamine for $48 \mathrm{~h}$.

\section{Detection of alkaline phosphatase activity in cultured osteoblasts}

In the present study, after screening drug concentration, cells were treated with $2.5 \mathrm{mg} / \mathrm{L}$ and $5 \mathrm{mg} / \mathrm{L} \mathrm{NaF}$ for 48 $\mathrm{h}$ and then treated with $5 \mu \mathrm{mol} / \mathrm{L}$ cyclopamine for $48 \mathrm{~h}$. Then ALP activity in osteoblasts was detected. The results revealed that in the F group, the ALP activity of osteoblasts was gradually increased; the change trend was basically the same as that of the cell proliferation rate.

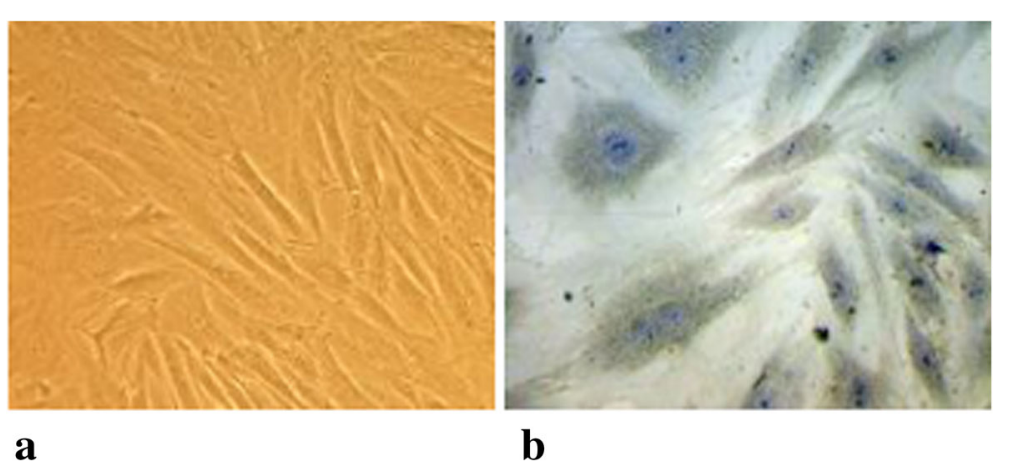

Fig. 1 Primary rat osteoblasts. a Primary rat osteoblasts, observed in the inverted position, $\times 200$. b Osteoblasts are stained with alkaline phosphatase $(\times 400)$ 


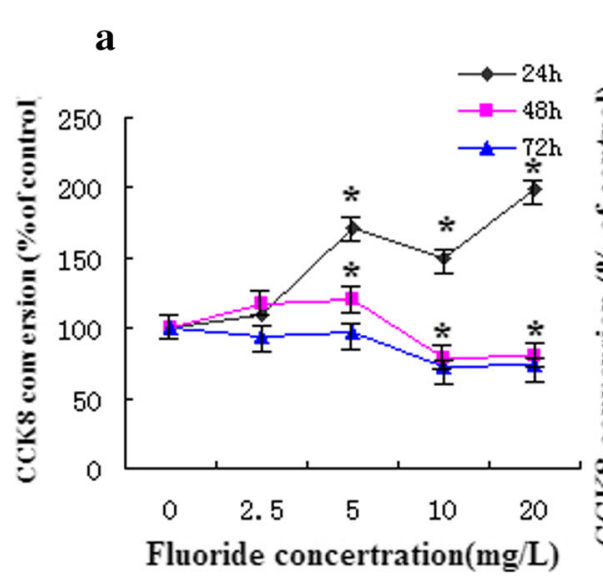

b

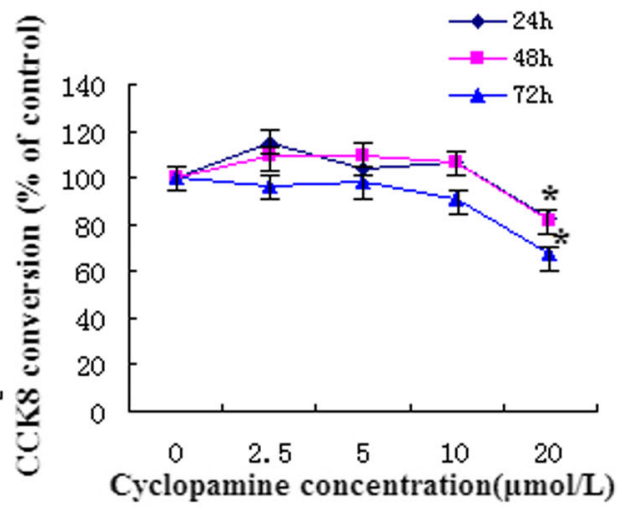

Fig. 2 The rate of cell proliferation treated with $\mathrm{NaF}$ or Cycl. a The rate of cell proliferation treated with NaF. b The rate of cell proliferation treated with $\mathrm{Cycl}$

The ALP activity was lower in the F + Cycl group than in the $\mathrm{F}$ group, and there was no significant difference between the F + DMSO group and the F group (Fig. 3).

\section{MRNA expressions of the Hh signaling pathway and} osteogenic-related factors in cultured osteoblasts

As shown by Fig. 4, with the increase in fluoride exposure dose, the expressions of Ihh, Smo, Gli2, and Runx2 in osteoblasts were increased gradually. The differences were statistically significant compared with the control group. Compared with the control group, in the $\mathrm{F}+\mathrm{Cycl}$ group, the expressions of all indexes were increased in the low-dose group and the dose group after treatment,

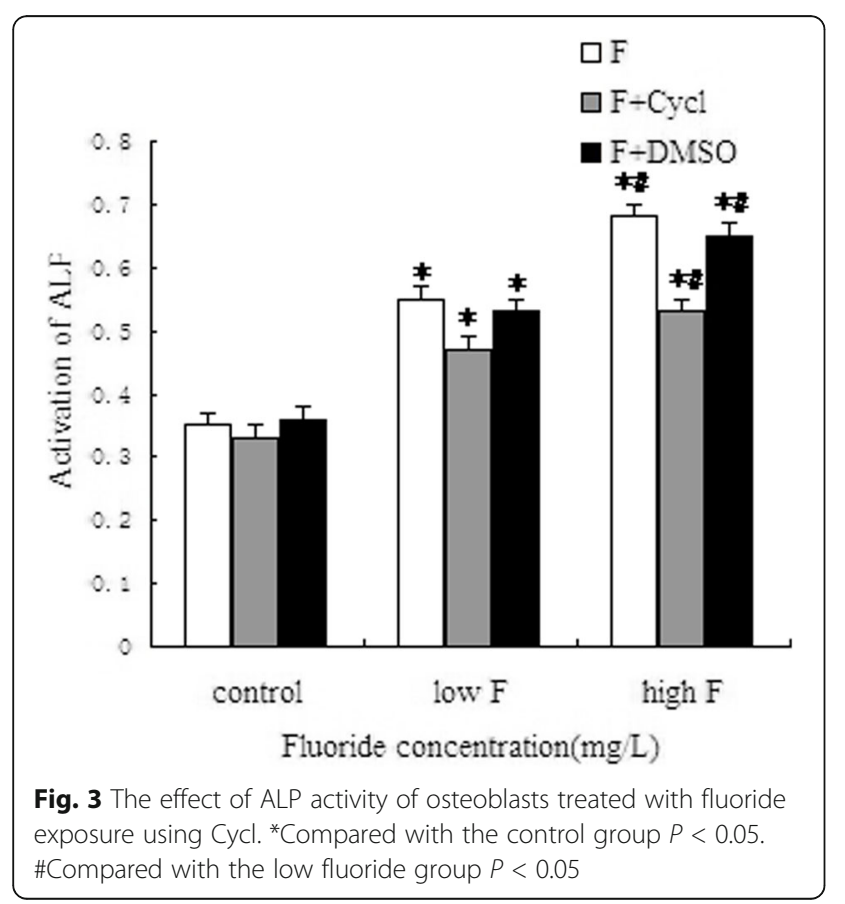

but the expressions were lower than that of the F subgroup with corresponding doses. There were no significant differences between the F + DMSO group and the F group.

Protein expressions of the Hh signaling pathway and osteogenic-related factors in cultured osteoblasts

As shown by Fig. 5, the protein expressions of all indexes were basically the same as the mRNA expressions of corresponding indexes. With the increase in fluoride exposure dose, the protein expressions of the Hh signal factors and osteogenic-related factors were gradually increased. The expressions of Ihh, Smo, Gli2, and Runx2 in the F + Cycl group were increased with the dose of fluoride but they were significantly inhibited compared with the $\mathrm{F}$ group. There were no significant differences in the protein expressions of all indexes between the F + DMSO group and the $\mathrm{F}$ group.

\section{Urinary fluoride content and serum bone alkaline phosphatase content in rats}

Compared with the control group, the urinary fluoride content in the $\mathrm{F}$ group was significantly higher $(P<$ $0.05)$, but there was no significant change in urinary fluoride content in the $\mathrm{F}+\mathrm{Cycl}$ group and the $\mathrm{F}+$ DMSO group. Compared with the control group, the serum BALP contents of rats in the other groups were increased after 6 months' intake of fluoride water $(P<$ 0.05). After drug blocking, the serum BALP content in the $\mathrm{F}+\mathrm{Cycl}$ group was lower than that in the $\mathrm{F}+$ DMSO group $(P<0.05)$. The serum BALP content in the $\mathrm{F}+\mathrm{DMSO}$ group was similar to that in the F group: it did not decrease (Table 1). 

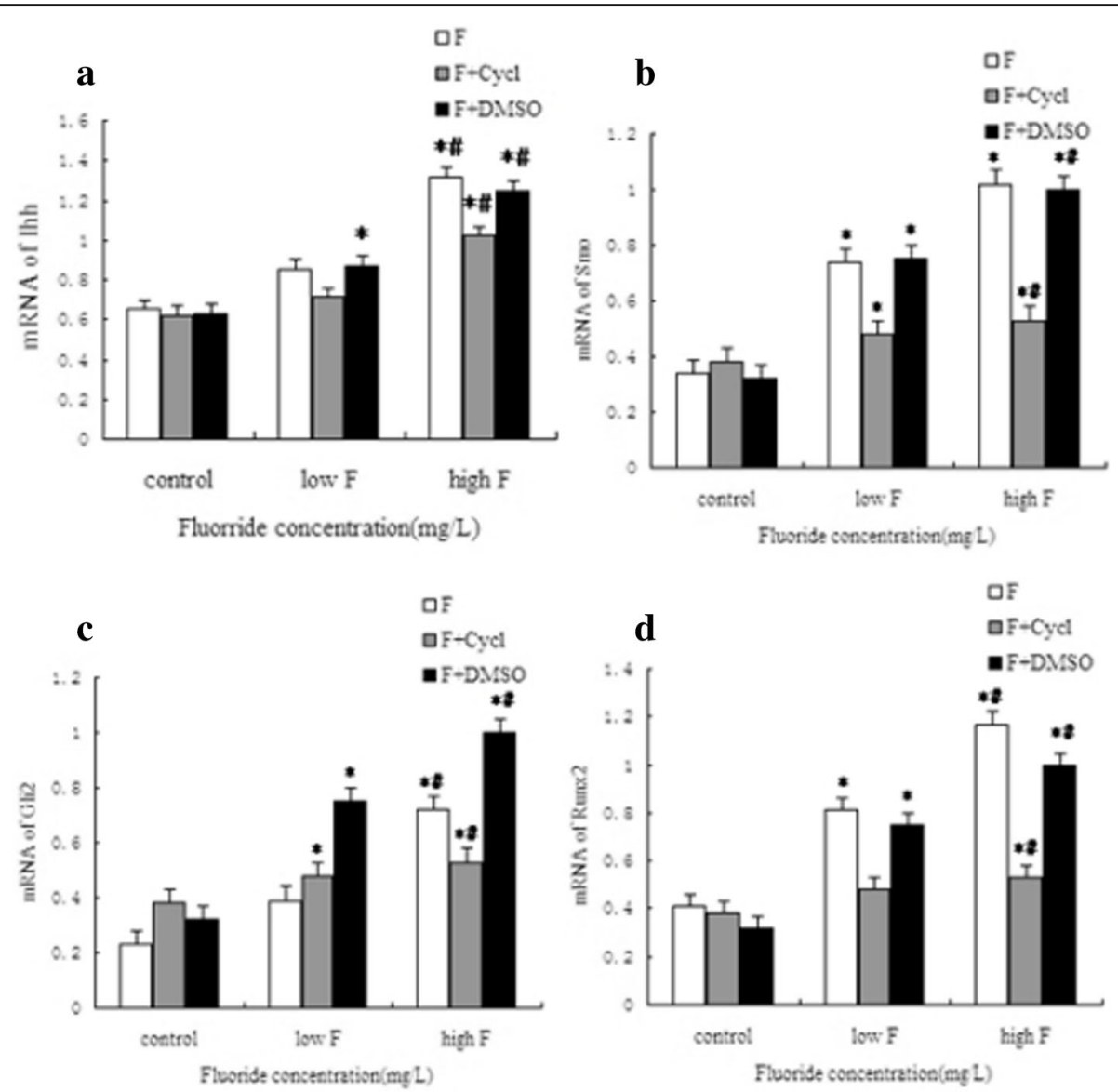

Fig. 4 The mRNA expressions of Ihh, Smo, Gli2, and Runx2 in osteoblasts treated with fluoride exposure influenced by Cycl. a-d Exhibit the mRNA expressions of Ihh, Smo, Gli2, and Runx2, respectively, in cultured osteoblasts. ${ }^{*}$ Compared with the control group $P<0.05$. \#Compared with the low fluoride group $P<0.05$

MRNA expressions of the Hh signaling pathway and osteogenic-related factors in bone tissue

The mRNA expressions of Ihh, Smo, Gli2, and Runx2 in the bone tissue of the F group were significantly higher than those in the control group $(P<0.05)$. After cyclopamine blocking, the expressions were decreased $(P<$ 0.05), but the differences between the F + DMSO group and $\mathrm{F}$ group were not statistically significant (Table 1).

\section{Protein expressions of the Hh signaling pathway and osteogenic-related factors in bone tissue}

Immunohistochemistry revealed that Ihh, Smo, Gli2, and Runx2 were all positively expressed in different degrees in osteoblasts of metaphysis, the expressions were all increased after exposure to fluoride, and the expressions were lower in the $\mathrm{F}+\mathrm{Cycl}$ group than in the $\mathrm{F}$ group and $\mathrm{F}+\mathrm{DMSO}$ group $(P<0.05)$ (Figs. 6 and 7$)$.

\section{Discussion}

In the present study, rats were fed with fluoride water for 6 months. Following this, the fluoride content in their urine was significantly higher than that of the control group. This suggests that the fluorosis model was established successfully. This study revealed that the serum BALP level was significantly higher in the F group than in the control group. After exposure to fluoride, the bone cortex thickened, the bone trabecular thickened, and bone trabecular density increased. Bone formation was obviously enhanced in rats with chronic fluorosis. However, the differences in bone morphometric indexes among the $\mathrm{F}$ group, $\mathrm{F}+\mathrm{Cycl}$ group and $\mathrm{F}+$ DMSO group were not statistically significant. The reason may be that changes in serological indexes appear before those in morphology. Thus, it is speculated that fluoride can enhance osteogenesis, and serum BALP can be used as a marker to judge the effect of fluoride on bone tissue.

Hedgehog is a secreted glycoprotein that can bind to the Patched (Ptch) receptor on the cell membrane and activate the effector Gli1 to change the structure of the receptor $[5,6]$. Lozito et al. carried out a comparative study on the regenerating tail and non-regenerating tail 

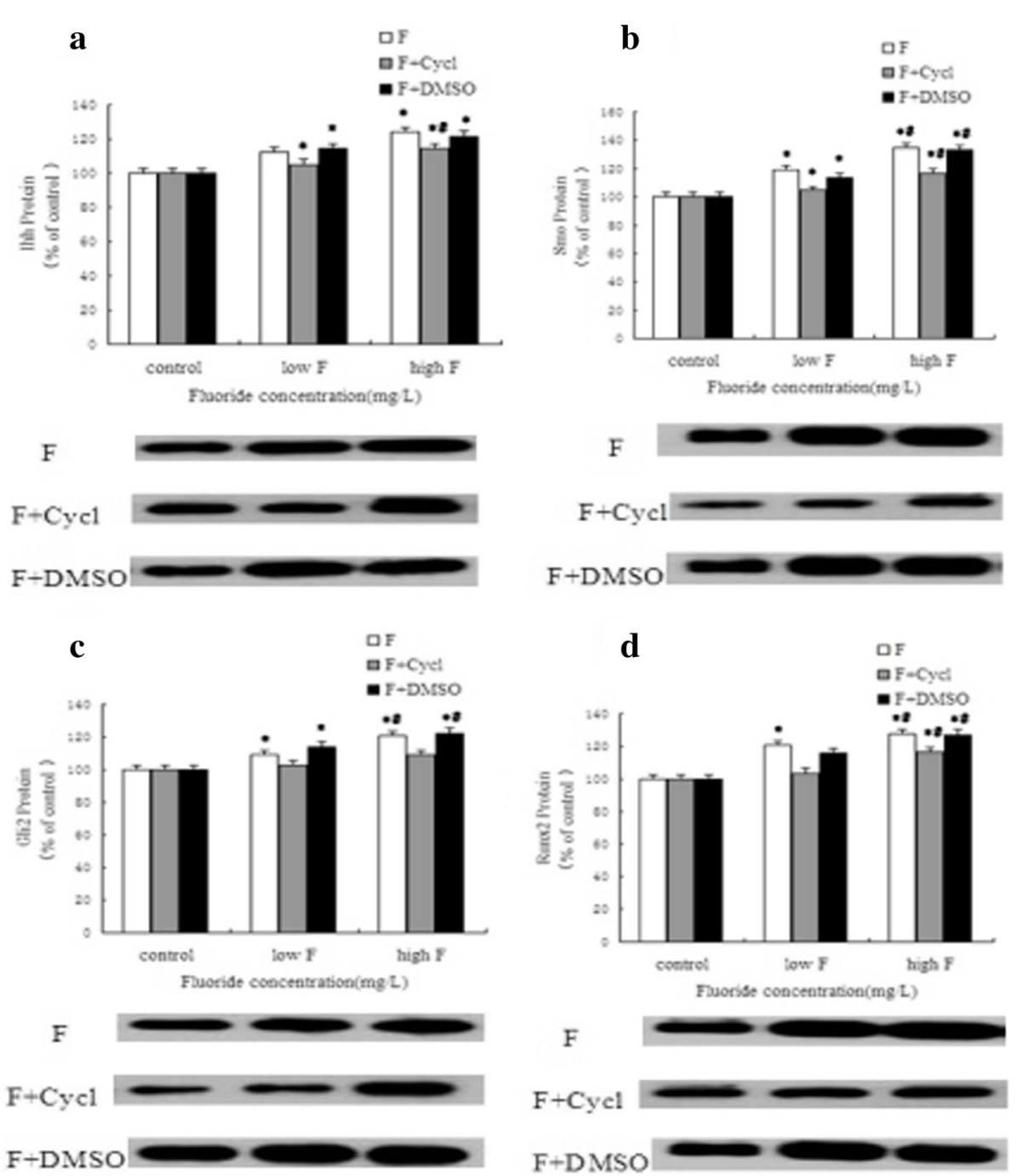

Fig. 5 The protein expressions of Ihh, Smo, Gli2, and Runx2 in osteoblasts treated with fluoride exposure using Cycl. a-d exhibit the protein expressions of Ihh, Smo, Gli2 and Runx2, respectively, in cultured osteoblasts. ${ }^{*}$ Compared with the control group $P<0.05$. \#Compared with the low fluoride group $P<0.05$

Table 1 Urine fluorine, serum BALP content and bone tissue Ihh, Shh, Ptch1, and Smo mRNA expression in each group

\begin{tabular}{llllllll}
\hline Groups & $\begin{array}{l}\text { The number of } \\
\text { cases }\end{array}$ & $\begin{array}{l}\text { The urinary fluoride content(mg/ } \\
\text { L) }\end{array}$ & BALP(IU/L) & Ihh & Smo & Gli2 & Runx2 \\
\hline Control group & 12 & $1.36 \pm 0.51$ & $27.78 \pm 4.09$ & $0.73 \pm 0.19$ & $0.14 \pm 0.04$ & $0.83 \pm 0.19$ & $0.37 \pm 0.10$ \\
F group & 12 & $7.60 \pm 0.61^{*}$ & $57.46 \pm 3.99^{*}$ & $1.39 \pm 0.36^{*}$ & $0.40 \pm 0.15^{*}$ & $1.40 \pm 0.31^{*}$ & $0.57 \pm 0.19^{*}$ \\
F + Cycl group & 12 & $7.55 \pm 0.32^{*}$ & $53.55 \pm$ & $0.81 \pm$ & $0.16 \pm$ & $0.75 \pm$ & $0.42 \pm$ \\
& & & $2.22^{* \# \&}$ & $0.28^{\# \&}$ & $0.03^{\# \&}$ & $0.17^{\# \&}$ & $0.09^{\# \&}$ \\
F + DMSO & 12 & $7.55 \pm 0.19^{*}$ & $57.56 \pm 4.23^{*}$ & $1.31 \pm 0.34^{*}$ & $0.39 \pm 0.10^{*}$ & $1.26 \pm 0.35^{*}$ & $0.55 \pm 0.17^{*}$ \\
group & & & & & & &
\end{tabular}

*Compared with control group, $P<0.05$

${ }^{\#}$ Compared with $\mathrm{F}$ group, $P<0.05$

${ }^{\&}$ Compared with F + DMSO group, $P<0.05$ 

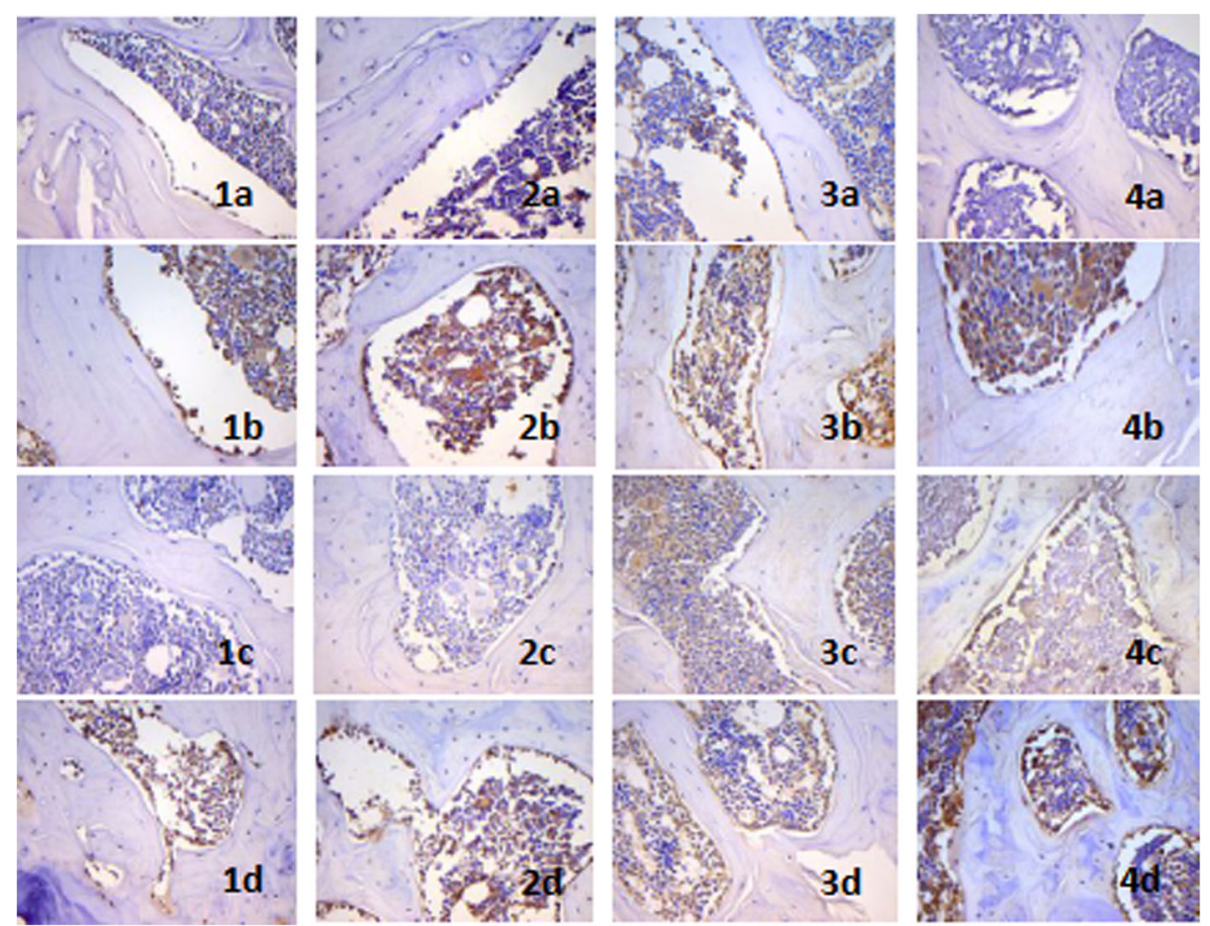

Fig. 6 The immunoreactivities of Ihh, Smo, Gli2, and Runx2 on osteoblasts in the experimental rats. a Control group. $\mathbf{b} \mathrm{F}$ group. $\mathbf{c}$ F + Cycl group. d F + DMSO group. 1. Ihh, 2. Smo, 3. Gli2, 4. Runx2, SP method ( $\times 400)$

of geckos [7]. The results confirmed that Ihh was involved in the ossification of the growth plate and participated in the ossification of the growth plates of different parts of the body through different mechanisms; the Ihh signal may increase bone formation [8]. Dysfunction in the Hh signal led to the destruction of bone development and bone balance [9]. In mature osteoblasts, selective upregulation of the Hh signal led to increased bone formation and excessive bone resorption [4]. These results are very similar to the pathological manifestations of osteofluorosis observed in previous studies. The molecules that mediate the bone-repair process in adulthood are Shh and Ihh in the Hh signaling pathway [9].

Cyclopamine, a specific blocker of the Hh signal, is an isosteroidal alkaloid. It can directly act on Smo and inhibit the activity of the Hh signal [10]. The present study was designed based on the methods of Sanchez [11] and Hirotsu et al. [12]. The half-maximal inhibitory concentration $\left(\mathrm{IC}_{50}\right)$ of cyclopamine was $2.5 \mu \mathrm{M}$, and $1-10 \mu \mathrm{M}$ cyclopamine can significantly inhibit the osteogenic differentiation of the mouse mesenchymal stem-cell line, C3H10T1/2. In addition, in the present study, real-time PCR revealed that the relative expressions of Ihh, Gli2, and Smo were increased in osteoblasts exposed to fluoride, and the mRNA and protein expressions of Ihh, Gli2, and Smo were also upregulated in the bone tissue of rats with fluorosis. After blocking with cyclopamine, the mRNA and protein expressions of Ihh, Gli2, and Smo were decreased. Therefore, the expression of Gli reflects the activation of the Hh signal. In the present study, Gli2 expression was significantly increased. This suggests that the Hh signal is activated in osteoblasts after exposure to fluoride. The investigators consider that after this signal is activated, excessive ligand $\mathrm{Hh}$ binds to Ptch, Smo is freed, and Smo promotes its activation factor Gli to enter the nucleus through the action of proteolytic enzyme, to enhance the transcription of the Hh signal target gene. The Ihh signal plays a critical role in the mineralization of the tendon end of fibrocartilage [13]. After blocking with cyclopamine, the decrease in osteoblast proliferation and differentiation ability and the decrease of serum BALP level can be partly attributed to the inhibition of Ihh expression.

There is a broad connection between the Hh signal and other signaling pathways. For example, knockdown of Ihh can inhibit the growth and differentiation of chondrocytes. The reason may be that it is closely related to the transforming growth factor- $\beta$ (TGF- $\beta$ )/ Smad and osteoprotegerin/receptor activator ofNF- $\mathrm{KB}$ ligand (OPG/RANKL) signaling pathways [14]. The results of previous studies revealed that exendin-4 can enhance ALP activation and mineralization nodule formation of osteoblasts, and can also promote the differentiation of osteoblast precursor cells into osteoblasts by upregulating the expressions of glucagon-like peptide-1 receptor, Hh, Gli1, Runx2, and osteocalein 

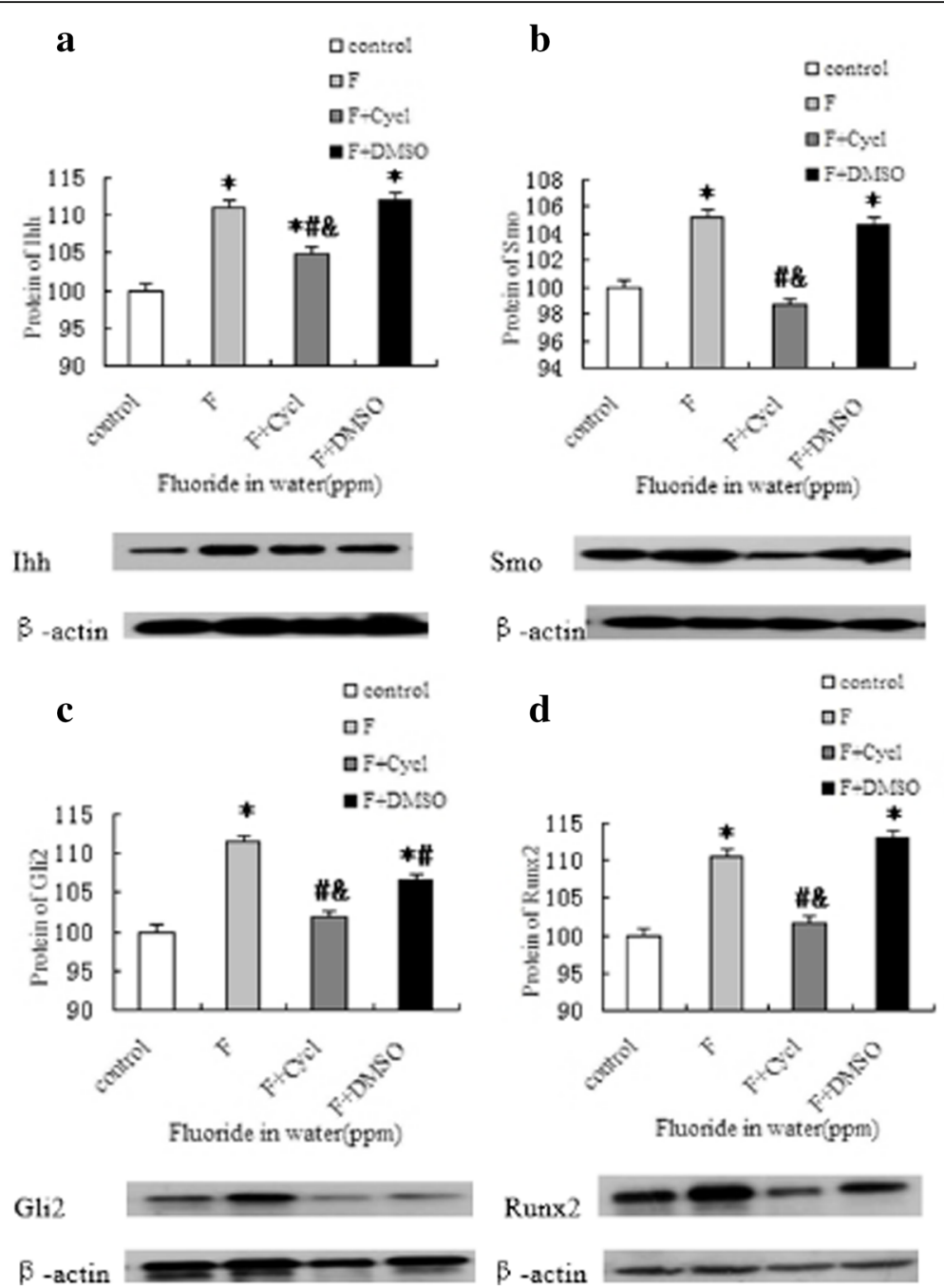

Fig. 7 The protein expressions of Ihh, Smo, Gli2, and Runx2 in the experimental rats' bone. a-d Exhibit the protein expressions of Ihh, Smo, Gli2, and Runx2, respectively, in bone tissue. ${ }^{*}$ Compared with the control group $P<0.05$. \#Compared with the $\mathrm{F}$ group $P<0.05, \&$ Compared with the F + DMSO group $P<0.05$

through the Hh/Gli1 pathway $[15,16]$. Runx2 can be expressed in undifferentiated mesenchymal stem cells and can directly regulate the expressions of Ihh, Gli1, and Patched-1(Ptc1) [17]. The results of this experiment revealed that after exposure to fluorine, the expressions of mRNA and the Runx2 protein were the same as those of the Hh signal factor. This suggests that in the process of osteoblast proliferation, Runx2 and $\mathrm{Hh}$ signals may regulate each other and induce osteoblast differentiation [18]. Fluoride can increase the protein and mRNA expressions of SHH, SMO, and GLI1 in liver cells of chronic fluorosis rats, and may be inhibited by cyclopamine. The $\mathrm{SHH}$ signaling pathway plays an important role in the pathogenesis of liver caused by fluorosis [19]. The analysis of the in vivo experiment revealed that overexpression of Gli1 could upregulate early osteogenesis-related factors; Gli1 could induce early osteogenic differentiation in a Runx2-dependent manner to a certain extent. In the absence of Runx2, overexpression of Ihh or Gli2 could not enhance the activity of ALP. Runx2 is a molecular marker of osteoblast proliferation and early differentiation. These results further confirm that the Hh signal is mainly responsible for the proliferation and differentiation of osteoblasts. The investigators consider that under the action of fluorine, the process is mainly that Ihh activates Gli2 to transcribe the signal into the nucleus to induce Runx2 expression through the mediation of Smo. In addition, it interacts with Ihh to promote the enhancement of ALP activity of osteoblasts and induce the vigorous proliferation of osteoblasts, causing osteosclerosis of the bone tissue. 


\section{Conclusion}

The Hh signal plays an important role in fluorideinduced bone injury. The effective inhibition of cyclopamine is expected to be a new target for the treatment of skeletal damage caused by fluorosis.

\begin{abstract}
Abbreviations
Hh: Hedgehog; SD: Sprague-Dawley; NaF: Sodium fluoride; ALP: Alkaline phosphatase; Ihh: Indian hedgehog; Smo: Smoothened; Gli: Gliomaassociated oncogene homolog; Runx2: Runt-related transcription factor 2; BALP: Bone alkaline phosphatase; SPF: Specific pathogen-free; DMSO: Dimethyl sulfoxide; EDTA: Ethylenediaminetetraacetic acid; H\&E: Hematoxylin and eosin; IHC: Immunohistochemistry; PMSF: Phenylmethylsulfonyl fluoride; RIPA: Radio-immunoprecipitation assay; PAGE: Polyacrylamide gel electrophoresis; PVDF: Electro-transferred to a polyvinylidene fluoride; TBS-T: Tris-buffered saline/Tween; BSA: Bovine serum albumin; LSD: Least significant difference; Ptch: Patched; OPG/ RANKL: Osteoprotegerin/receptor activator of NF-KB ligand; TGF$\beta$ : Transforming growth factor- $\beta$; Ptc1: Patched-1
\end{abstract}

\section{Authors' contributions}

DCN and XL conceived the idea and conceptualized the study. ZLN and LHY collected the data. DCN and ZY analyzed the data. DCN and XL drafted the manuscript, then YYN reviewed the manuscript. All authors read and approved the final draft.

\section{Funding}

The National Nutural Science Foundation of China (U1812403): The Nationa Nutural Science Foundation of China (81260419); The Ministry of Education of Doctoral Fund (class tutors) in China (20125215110001); Guizhou Province Science and Technology Cooperation Program Project ([2017]7192); Guizhou Provincial Natural Science Foundation ([2018]1135); Guizhou Medical University 2018 Academic New Seedling Cultivation and Innovative Exploration Special Project ([2018]5779-37); Guizhou Provincial Graduate Research Fund (KYJJ2017010); Doctoral Initiates Foundation of Guiyang Medical College ([2014]013).

\section{Availability of data and materials}

We declared that materials described in the manuscript, including all relevant raw data, will be freely available to any scientist wishing to use them for non-commercial purposes, without breaching participant confidentiality.

\section{Ethics approval and consent to participate}

The authors confirm that they have read the Editorial Policy pages. This study was conducted with approval from the Ethics Committee of our hospital. This study was conducted in accordance with the Declaration of Helsinki. Written informed consent was obtained from all participants.

\section{Consent for publication}

Not applicable

\section{Competing interests}

The authors declare that they have no competing interests.

\section{Author details}

'Department of Pathology, Affiliated Hospital of GuiZhou Medical University, No. 28 of Guiyi Street, Guiyang 550004, China. ${ }^{2}$ Department of Pathology, GuiZhou Medical University, Guiyang 550004, China. ${ }^{3}$ Guiyang Maternal and Child Care Hospital, 550004 Guiyang, China.

Received: 16 December 2020 Accepted: 9 February 2021

Published online: 26 February 2021

\section{References}

1. Idon PI, Enabulele JE. Prevalence, severity, and request for treatment of dental fluorosis among adults in an endemic region of Northern Nigeria. Eur J Dentistry. 2018;12(2):184.

2. Chambers TJ, Hall TJ. Cellular and molecular mechanisms in the regulation and function of osteoclasts. Vitam Horm. 1991;46:41-6.
3. Garcia-Gonzalo FR, Phua SC, Roberson EC, Garcia G 3rd, Abedin M, Schurmans $S$, Inoue T, Reiter JF. Phosphoinositides regulate ciliary protein trafficking to modulate hedgehog signaling. Dev Cell. 2015;34:400-9.

4. Mak KK, Bi Y, Wan C, Chuang PT, Clemens T, Young M, Yang Y. Hedgehog signaling in mature osteoblasts regulates bone formation and resorption by controlling pthrp and rankl expression. Dev Cell. 2008;14(5):674-88.

5. Cai X, Yu K, Zhang L, Li Y, Li Q, Yang Z, Shen T, Duan L, Xiong W, Wang W. Synergistic inhibition of colon carcinoma cell growth by Hedgehog-Gli1 inhibitor arsenic trioxide and phosphoinositide 3-kinase inhibitor LY294002. Onco Targets Ther. 2015;8:877-83.

6. Varjosalo M, Taipale J. Hedgehog: functions and mechanisms. Genes Dev. 2008;22:2454-72.

7. Lozito TP, Tuan RS. Lizard tail regeneration: regulation of two distinct cartilage regions by Indian hedgehog. Dev Biol. 2015;399(2):249-62.

8. Cai H, Liu A. Spop promotes skeletal development and homeostasis by positively regulating Ihh signaling. Proc Natl Acad Sci USA. 2016;113: 14751-6.

9. $\quad$ Yang J, Andre $P$, Ye L, Yang YZ. The Hedgehog signalling pathway in bone formation. Int J Oral Sci. 2015;7:73-9.

10. Ruiz-Heiland G, Horn A, Zerr P, Hofstetter W, Baum W, Stock M, Distler JH, Nimmerjahn F, Schett G, Zwerina J. Blockade of the hedgehog pathway inhibitis osteophyte formation in arthritis. Ann Rheum Dis. 2012;71(3):400-7.

11. Sanchez P, Ruiz i Altaba A. In vivo inhibition of endogenous brain tumors through systemic interference of Hedgehog signaling in mice [J]. Mech Dev. 2005;122(2):223-30.

12. Hirotsu M, Setoguchi $T$, Sasaki $H$, Matsunoshita $Y$, Gao $H$, Nagao $H$, Kunigou O, Komiya S. Smoothened as a new therapeutic target for human osteosarcoma [J]. Mol Cancer. 2010;9:5.

13. Bechtold TE, Saunders C, Decker RS, Um HB, Cottingham N, Salhab I, Kurio N, Billings PC, Pacifici M, Nah HD, Koyama E. Osteophyte formation and matrix mineralization in a TMJ osteoarthritis mouse model are associated with ectopic hedgehog signaling. Matrix Biol. 2016;52-54:339-54.

14. Deng A, Zhang H, Hu M, Liu S, Wang Y, Gao Q, Guo C. The inhibitory roles of Ihh downregulation on chondrocyte growth and differentiation. Exp Ther Med. 2018;15(1):789-94.

15. Gao L, Li S, Li Y. Exendin-4 promotes the osteogenic differentiation of osteoblasts via the Hedgehog/Gli1 signaling pathway. Am J Transl Res. 2018;10(1):315-24

16. Shimoyama A, Wada M, Ikeda F, Hata K, Matsubara T, Nifuji A, Noda M, Amano K, Yamaguchi A, Nishimura R, Yoneda T. Ihh/Gli2 signaling promotes osteoblast differentiation by regulating Runx2 expression and function. Mol Biol Cell. 2007:18(7):2411-8.

17. Qin X, Jiang Q, Miyazaki T, Komori T. Runx2 regulates cranial suture closure by inducing hedgehog, Fgf, Wnt, and Pthlh signaling pathway gene expression in suture mesenchymal cells. Hum. Mol. Genet. 2018;28:896-911.

18. Komori T. Regulation of proliferration, differentiation and functions of osteoblasts by Runx2. Int J Mol Sci. 2019;20(7):1-11.

19. Zhao L, Yu Y, Deng C. Protein and mRNA expression of Shh, Smo and Gli1 and inhibition by cyclopamine in hepatocytes of rats with chronic fluorosis. Toxicology Letters. 2014;225(2):318-24.

\section{Publisher's Note}

Springer Nature remains neutral with regard to jurisdictional claims in published maps and institutional affiliations.

\section{Ready to submit your research? Choose BMC and benefit from:}

- fast, convenient online submission

- thorough peer review by experienced researchers in your field

- rapid publication on acceptance

- support for research data, including large and complex data types

- gold Open Access which fosters wider collaboration and increased citations

- maximum visibility for your research: over $100 \mathrm{M}$ website views per year

At BMC, research is always in progress.

Learn more biomedcentral.com/submission 